\title{
'Young blood' anti-ageing mechanism called into question
}

A prote in in the blood of young mice that seemed to rejuvenate older animals may do the opposite.

\section{Sara Reardon}

19 May 2015

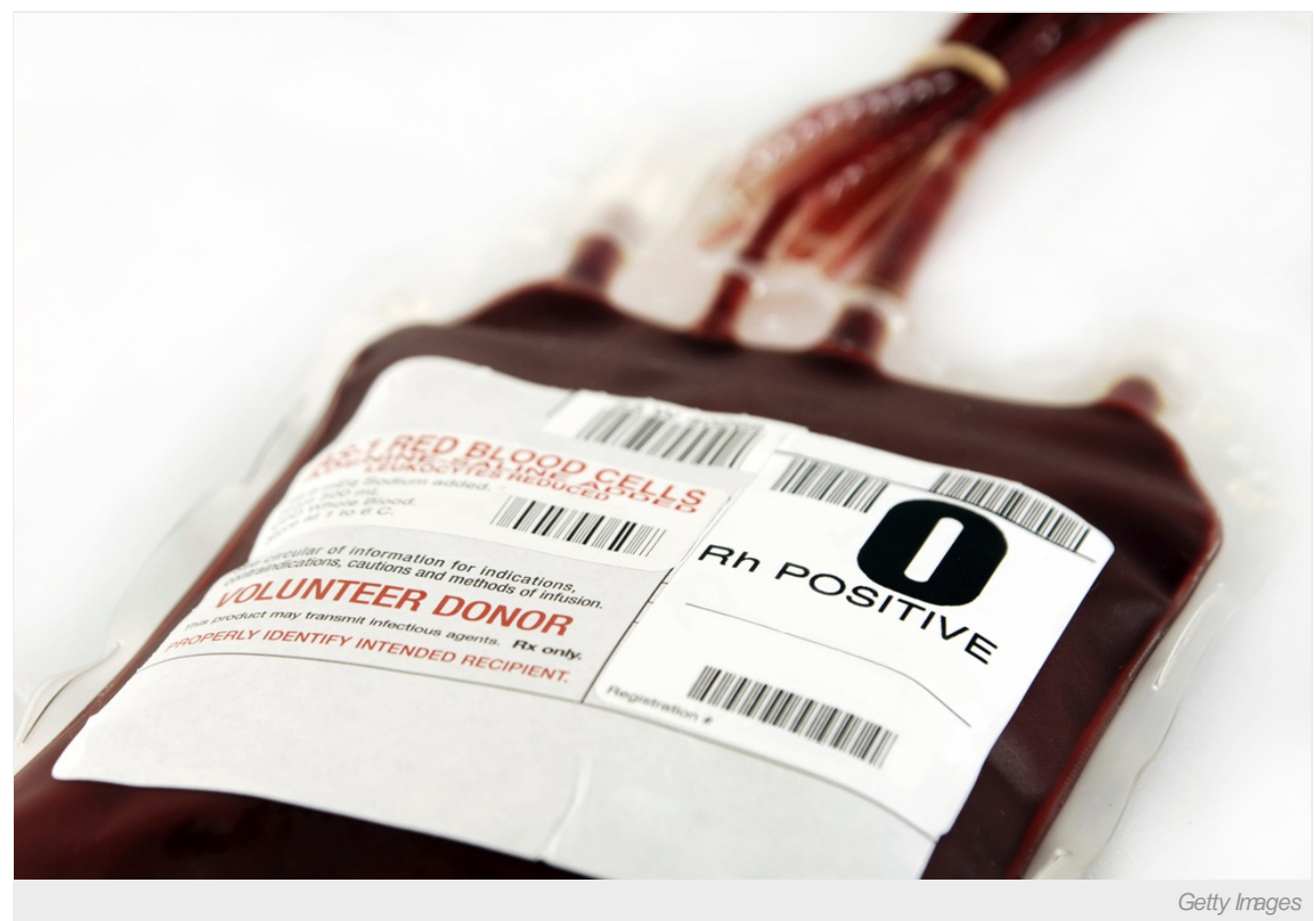

Blood from young animals seems to regenerate muscles in older ones, but researchers have not yet pinned down why.

The hunt for the fountain of youth is back to square one - at least for those seeking it in blood. New findings cast doubt on research that attempted to explain why the muscles of an old animal can be rejuvenated with a dose of blood from a young animal.

For decades, scientists have sought to understand the anti-ageing effects of parabiosis, a technique in which researchers sew a young mouse and an old mouse together so that they share a circulatory system. The young mouse's blood seems to rejuvenate the old mouse, regenerating its wasting muscles and restoring its cognitive abilities. On the basis of those results, at least one company is attempting to replicate the effect in humans using blood plasma from healthy young people to treat patients with Alzheimer's disease.

In 2013, a team led by Amy Wagers, a stem-cell researcher at Harvard University in Cambridge, Massachusetts, seemed to offer an explanation for this blood-doping effect ${ }^{1}$. The scientists found that levels of a protein called GDF11 decreased in the blood of mice as they grew older. When the researchers injected the protein into the heart muscle of old mice, it became 'younger' — thinner and better able to pump blood. Two subsequent studies by Wagers and her colleagues found that GDF11 boosted the growth of new blood vessels and neurons in the brain ${ }^{2}$ and spurred stem cells to regenerate skeletal muscle at the sites of injuries ${ }^{3}$.

\section{Rejuvenation riddle}

Those results quickly made GDF11 the leading explanation for the rejuvenating effects of transfusing young blood into old animals. But that idea was confusing to many because GDF11 is very similar to the protein myostatin, which prevents muscle stem cells from differentiating into mature muscle — the opposite effect to that seen by Wagers and her team.

For GDF11, "You could imagine that when it came out last year that it helped muscle, it was quite a surprise," says David Glass, executive director of the muscle diseases group at the Novartis Institutes for Biomedical Research in Cambridge, Massachusetts. "Did we miss something?" 
reagents that Wagers' group had used to measure GDF11 levels, and found that these chemicals could not distinguish between myostatin and GDF11. When the Novartis team used a more specific reagent to measure GDF11 levels in the blood of both rats and humans, they found that GDF11 levels actually increased with age — just as levels of myostatin do. That contradicts what Wagers' group had found.

Glass's team next used a combination of chemicals to injure a mouse's skeletal muscles, and then regularly injected the animal with three times as much GDF11 as Wagers and her team had used. Rather than regenerating the muscle, Glass found, GDF11 seemed to make the damage worse by inhibiting the muscles' ability to repair themselves. He and his colleagues report their results on 19 May in Cell Metabolism ${ }^{4}$.

Glass says that although his group's results do not explain why parabiosis works, they could help to explain the mechanism behind bimagrumab, an experimental Novartis treatment for muscle weakness and wasting. The drug, which is currently in clinical trials, blocks myostatin — and perhaps GDF11 as well.

\section{Meticulous methods}

Thomas Rando, a stem-cell biologist at Stanford University in California, praises the attention to detail in the methods used by Glass and his team. "They did a very thorough and rigorous job," he says. He does not see the findings as a setback for the field, because they confirmed what researchers had expected before the studies by Wagers and her colleagues. "If this paper was published first, it would not have been surprising," he says.

Wagers, however, stands by her findings. She says that although at first glance the Novartis group's data seem to conflict with her team's results, there could be multiple forms of GDF11 and that perhaps only one decreases with age. Both papers suggest that having either too much or too little GDF11 could be harmful, she says. She adds that the Novartis group injured the muscle more extensively and then treated it with more GDF11 than her group had done, so the results may not be directly comparable.

"We look forward to addressing the differences in the studies with additional data very soon," Wagers says.

Rando expects that researchers will now investigate the finding ${ }^{2}$ that GDF11 affects the growth of neurons and blood vessels in the brain. "I'm not sure which result is going to stand the test of time," he says.

Nature | doi:10.1038/nature.2015.17583

\section{References}

1. Loffredo, F. S. et al. Cell 153, 828-839 (2013).

2. Katsimpardi, L. et al. Science 344, 630-634 (2014).

3. Sinha, M. et al. Science 344, 649-652 (2014).

4. Egerman, M. A. et al. Cell Metab. http://dx.doi.org/10.1016/j.cmet.2015.05.010 (2015). 